\title{
Single-frequency blue light generation by single-pass sum-frequency generation in a coupled ring cavity tapered laser
}

\author{
Jensen, Ole Bjarlin; Petersen, Paul Michael
}

\section{Published in:}

Applied Physics Letters

Link to article, DOI:

$10.1063 / 1.4823821$

Publication date:

2013

Document Version

Publisher's PDF, also known as Version of record

Link back to DTU Orbit

Citation (APA):

Jensen, O. B., \& Petersen, P. M. (2013). Single-frequency blue light generation by single-pass sum-frequency generation in a coupled ring cavity tapered laser. Applied Physics Letters, 103(14), [141107].

https://doi.org/10.1063/1.4823821

\section{General rights}

Copyright and moral rights for the publications made accessible in the public portal are retained by the authors and/or other copyright owners and it is a condition of accessing publications that users recognise and abide by the legal requirements associated with these rights.

- Users may download and print one copy of any publication from the public portal for the purpose of private study or research.

- You may not further distribute the material or use it for any profit-making activity or commercial gain

- You may freely distribute the URL identifying the publication in the public portal 


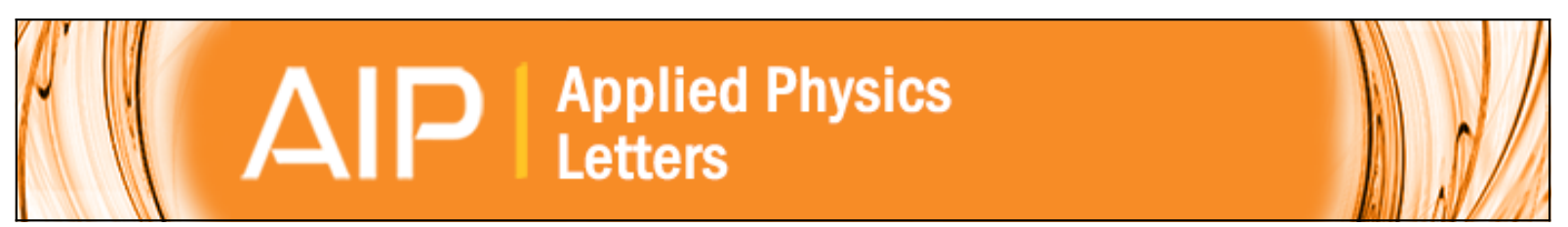

Single-frequency blue light generation by single-pass sum-frequency generation in a coupled ring cavity tapered laser

Ole Bjarlin Jensen and Paul Michael Petersen

Citation: Applied Physics Letters 103, 141107 (2013); doi: 10.1063/1.4823821

View online: http://dx.doi.org/10.1063/1.4823821

View Table of Contents: http://scitation.aip.org/content/aip/journal/apl/103/14?ver=pdfcov

Published by the AIP Publishing

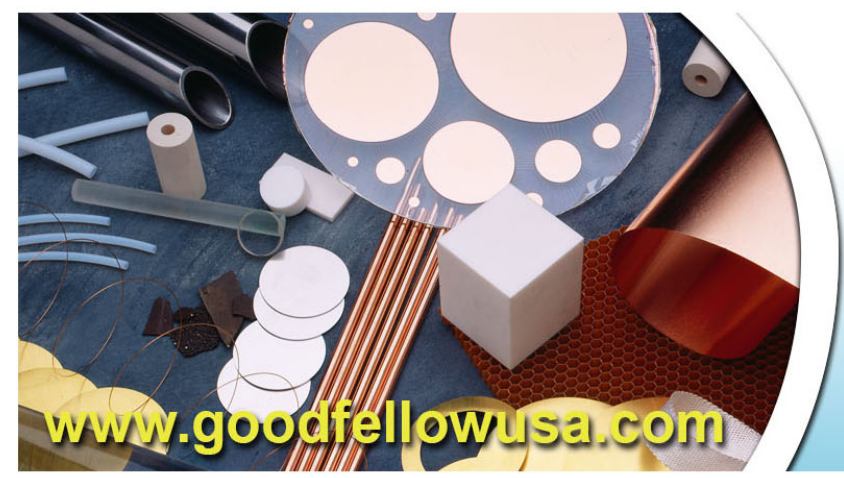

BODIFEl|OII

metals • ceramics $\cdot$ polymers composites • compounds • glasses

Save $5 \%$ B Buy online 70,000 products $\cdot$ Fast shipping 


\title{
Single-frequency blue light generation by single-pass sum-frequency generation in a coupled ring cavity tapered laser
}

\author{
Ole Bjarlin Jensen ${ }^{\text {a) }}$ and Paul Michael Petersen \\ DTU Fotonik, Department of Photonics Engineering, Technical University of Denmark, \\ DK-4000 Roskilde, Denmark
}

(Received 4 July 2013; accepted 15 September 2013; published online 1 October 2013)

\begin{abstract}
A generic approach for generation of tunable single frequency light is presented. $340 \mathrm{~mW}$ of near diffraction limited, single-frequency, and tunable blue light around $459 \mathrm{~nm}$ is generated by sumfrequency generation (SFG) between two tunable tapered diode lasers. One diode laser is operated in a ring cavity and another tapered diode laser is single-passed through a nonlinear crystal which is contained in the coupled ring cavity. Using this method, the single-pass conversion efficiency is more than $25 \%$. In contrast to SFG in an external cavity, the system is entirely self-stabilized with no electronic locking. (C) 2013 AIP Publishing LLC. [http://dx.doi.org/10.1063/1.4823821]
\end{abstract}

Visible laser sources with the possibility of selecting the desired wavelength are interesting to a number of applications including spectroscopy and bio-photonics. Visible diode lasers have appeared in various spectral regions including the blue, green, and red. Single-mode visible diode lasers, however, are limited to output powers of about $100 \mathrm{~mW}$ with multi-longitudinal mode operation while multi-spatial mode lasers are available with watt-level output powers. Visible external cavity single-mode diode lasers emit singlefrequency light with even lower output power and the tuning is limited to a few nanometers. Second harmonic generation (SHG) is often used to generate light in this spectral region but due to the lack of gain media at various wavelengths, the spectral coverage is limited. Optical parametric oscillators are very flexible sources for generation of almost any wavelength but they are complicated to operate and they require both high power and high quality pump sources. Sum-frequency generation (SFG) has proven to be very agile in terms of the generated wavelengths. Simple single-pass SFG has been implemented and have generated tens and hundreds of $\mathrm{mW}$ at the Sodium D2 resonance at $589 \mathrm{~nm}$ using diode pumped solid state lasers (DPSSL) as the pump source. ${ }^{1,2}$ Blue light generation at $492 \mathrm{~nm}$ was demonstrated by SFG of a DPSSL and a diode laser ${ }^{3}$ and recently almost $4 \mathrm{~W}$ of green light was obtained by SFG of two beam combined distributed Bragg reflector (DBR) tapered diode lasers. ${ }^{4}$ Increased conversion efficiency can be obtained by enhancing the power in the nonlinear crystal. Singly resonant systems have been demonstrated with the nonlinear crystal placed either inside the cavity of a laser ${ }^{5-9}$ or in an external enhancement cavity. ${ }^{10} \mathrm{~A}$ conversion efficiency of more than $41 \%$ of the single-pass laser power has been demonstrated. ${ }^{6}$ Even higher conversion efficiencies can be obtained in doubly resonant systems, where both interacting fundamental wavelengths are resonated in either a laser cavity ${ }^{11}$ or an enhancement cavity. ${ }^{12}$ These systems tend to become unstable and require electronic locking for stable operation. Coupled cavity operation of tapered amplifiers has recently been demonstrated to provide

\footnotetext{
${ }^{\text {a) }}$ Author to whom correspondence should be addressed. Electronic mail: ojen@fotonik.dtu.dk.
}

high output power in the visible range by $\mathrm{SHG} .{ }^{13,14}$ In the present paper, we expand this approach to include SFG.

We present a generic method for efficient generation of visible light by SFG between light emitted by two tapered diode lasers. The power of one laser is enhanced using a coupled cavity approach and the single-pass conversion efficiency is increased to more than $25 \%$. This results in the generation of more than $300 \mathrm{~mW}$ single-frequency light at $459 \mathrm{~nm}$. The method can easily be expanded to cover the full visible spectrum. The frequency of the resonated laser is passively locked to the resonance frequency of the enhancement cavity by use of optical feedback.

The experimental setup is shown in Fig. 1. In the coupled ring cavity similar to the one used by Jensen et al., ${ }^{14}$ a tapered amplifier designed for operation around $1060 \mathrm{~nm}$ and tunable in the $1049-1093 \mathrm{~nm}$ range is used. The fast axis of the tapered amplifier is collimated using an aspherical lens (L1) with $3.1 \mathrm{~mm}$ focal length and a numerical aperture of 0.68. This lens focuses the light in the slow axis due to astigmatism in the tapered amplifier. A cylindrical lens (L2)

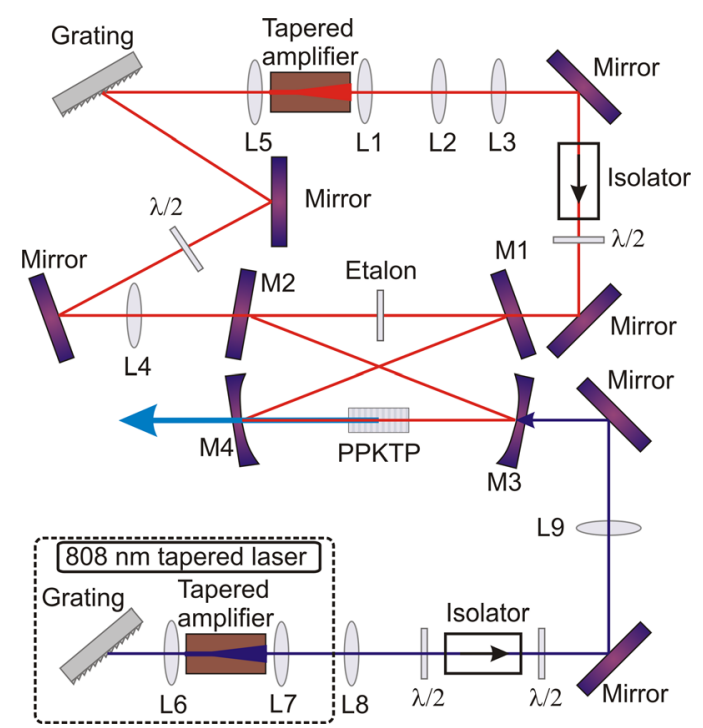

FIG. 1. Schematic layout of the experimental setup for tunable SFG around $459 \mathrm{~nm}$. 
with $30 \mathrm{~mm}$ focal length is used to correct for astigmatism and collimate the beam in the slow axis. A spherical lens (L3) with $250 \mathrm{~mm}$ focal length is used to couple the beam from the tapered amplifier to the enhancement cavity. An optical isolator with $>30 \mathrm{~dB}$ isolation is inserted to ensure unidirectional operation and a half wave plate is used to rotate the polarization to horizontal which fits with the phase matching conditions of the nonlinear crystal. The enhancement cavity is designed as a four mirror bow-tie cavity with two plane mirrors (M1 and M2) and two mirrors with $50 \mathrm{~mm}$ radius of curvature (M3 and M4). Mirror M1 is coated for $95 \%$ reflectivity at $1064 \mathrm{~nm}$ and $\mathrm{M} 2$ has $98 \%$ reflectivity at $1064 \mathrm{~nm}$. These reflectivities proved to be a good compromise between obtaining high circulating power in the cavity and still permitting enough leakage power to saturate the tapered amplifier. Mirror M3 is coated for high reflectivity at $1064 \mathrm{~nm}$ and highly transmitting at $808 \mathrm{~nm}$ while mirror M4 is coated for high reflectivity at $1064 \mathrm{~nm}$ and highly transmitting at $532 \mathrm{~nm}$. M4 has a residual reflectivity of about $10 \%$ at $459 \mathrm{~nm}$. The distance between M3 and M4 is about $67 \mathrm{~mm}$ and the remaining distance is about $207 \mathrm{~mm}$. This cavity supports a mode with a beam diameter of approximately $60 \mu \mathrm{m}$ by $70 \mu \mathrm{m}$ between the curved mirrors. Here, a $10 \mathrm{~mm}$ long periodically poled potassium titanyl phosphate (PPKTP) crystal (Raicol) is placed. The PPKTP crystal has a poling period of $5.6 \mu \mathrm{m}$ for SFG between light at $1064 \mathrm{~nm}$ and $808 \mathrm{~nm}$ and anti-reflection (AR) coated at interacting wavelengths. An un-coated un-doped YAG etalon with a thickness of $125 \mu \mathrm{m}$ is included in the cavity to increase stability. The light exiting the cavity through M2 is collimated using a spherical lens (L4) with a focal length of $100 \mathrm{~mm}$. A diffraction grating with 1200 grooves per $\mathrm{mm}$ is used to select the operating wavelength and a half wave plate is inserted in the beam path to control the polarization incident on the grating. The power coupled to the ridge section of the tapered amplifier can be controlled by rotation of the polarization as the grating diffraction efficiency is polarization dependent. The light is coupled into the ridge section using an aspherical lens (L5) with $3.1 \mathrm{~mm}$ focal length.

The $808 \mathrm{~nm}$ tapered laser consists of an $808 \mathrm{~nm}$ tapered amplifier operated in the Littrow geometry. ${ }^{15}$ It is collimated using a combination of an aspherical lens (L7) with $3.1 \mathrm{~mm}$ focal length and a cylindrical lens (L8) with $40 \mathrm{~mm}$ focal length. The light passes an optical isolator with $>30 \mathrm{~dB}$

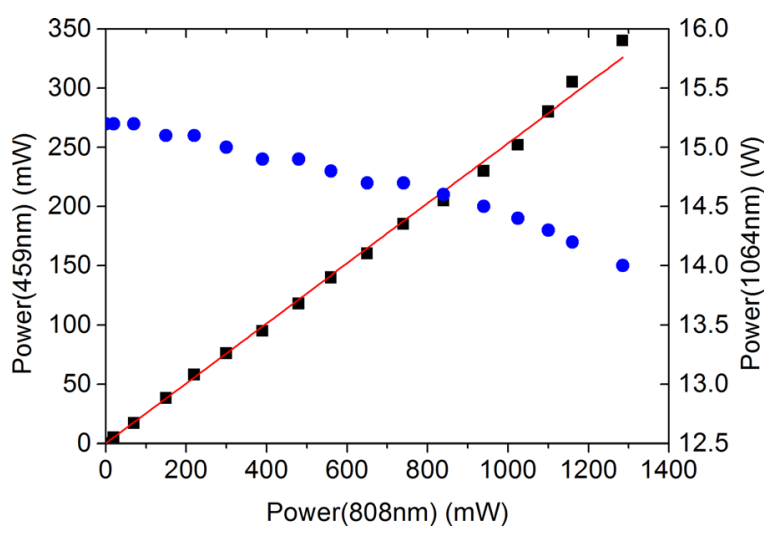

FIG. 2. Output power at $459 \mathrm{~nm}$ (squares) and circulating power at $1063.5 \mathrm{~nm}$ (dots) versus power at $808 \mathrm{~nm}$. isolation and two half-wave plates, which are used to control the power and the polarization incident on the PPKTP crystal. A $60 \mathrm{~mm}$ focal length lens (L9) is used to focus the light into the PPKTP crystal. The $808 \mathrm{~nm}$ tapered laser provides up to $1.28 \mathrm{~W}$ of output power after the optical isolator and the beam propagation factor is $\mathrm{M}^{2}=1.3 \times 1.9$ (vertical $\times$ horizontal). The laser is tunable in the $792-819 \mathrm{~nm}$ spectral region (FWHM).

The wavelength of the $1060 \mathrm{~nm}$ tapered amplifier operated in the coupled cavity is tuned to $1063.5 \mathrm{~nm}$ to facilitate phase matching with the incoming $807.5 \mathrm{~nm}$ light at a temperature of $34^{\circ} \mathrm{C}$ in the PPKTP crystal. The power in the enhancement cavity can be monitored by the power leaking through the cavity mirrors M3 or M4, when their reflectivities are known.

The power characteristics are shown in Fig. 2. An output power of $340 \mathrm{~mW}$ at $459 \mathrm{~nm}$ is obtained with $14 \mathrm{~W}$ circulating power in the cavity and $1.28 \mathrm{~W}$ of single-pass power at $807.5 \mathrm{~nm}$. In Figure 2, it is also seen that the cavity power is decreased due to the extra induced losses by the SFG process. The losses due to SFG are linear in terms of the incident power allowing for higher circulating power compared to SHG where the losses are quadratic. ${ }^{14}$ The increased losses at high single-pass power will increase the coupling into the cavity as the input mirror M1 transmission ideally should match the losses in the cavity. Taking into account the losses in the measurement of the generated power through dichroic mirrors and the transmission of M4, more than $400 \mathrm{~mW}$ are generated at $459 \mathrm{~nm}$. This corresponds to a single-pass power conversion efficiency of $31.3 \%$ and a conversion efficiency in the PPKTP crystal of $2.2 \% / \mathrm{W}$.

The spectrum of the generated blue light is determined by the spectrum of the two mixing lasers. The spectra of all three interacting waves are shown in Fig. 3. Here, the measured linewidth at $459 \mathrm{~nm}$ is $2 \mathrm{pm}$, limited by the resolution of the optical spectrum analyser (Advantest Corp. Q8347). The linewidth of the $459 \mathrm{~nm}$ light could not be measured directly due to lack of suitable mirrors for a scanning Fabry Perot Interferometer (FPI). The linewidths of the two mixing lasers were measured and the scanning FPI traces are shown in Fig. 4. In both cases the measured linewidth was limited by the resolution of the FPI which was $12 \mathrm{MHz}$ at $808 \mathrm{~nm}$ and $10 \mathrm{MHz}$ at $1064 \mathrm{~nm}$, respectively. This indicates that the light at $459 \mathrm{~nm}$ is also single-frequency.

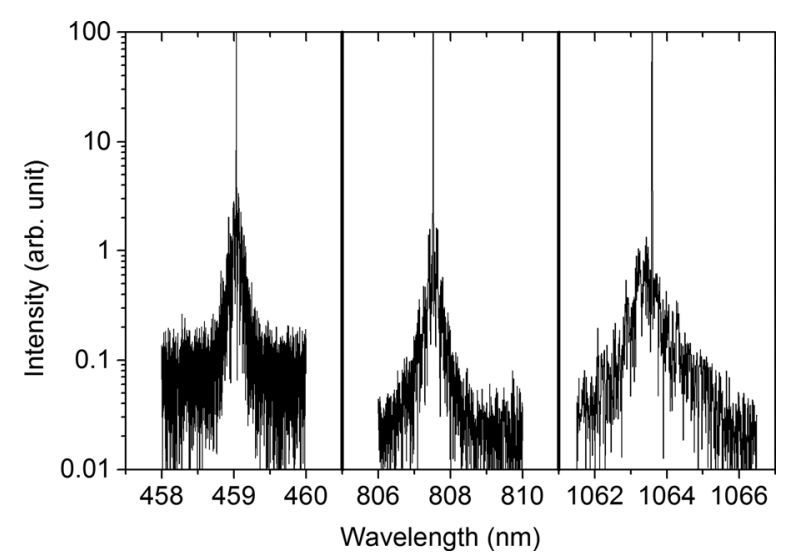

FIG. 3. Spectra of the three waves at $459 \mathrm{~nm}, 807.5 \mathrm{~nm}$, and $1063.5 \mathrm{~nm}$. 

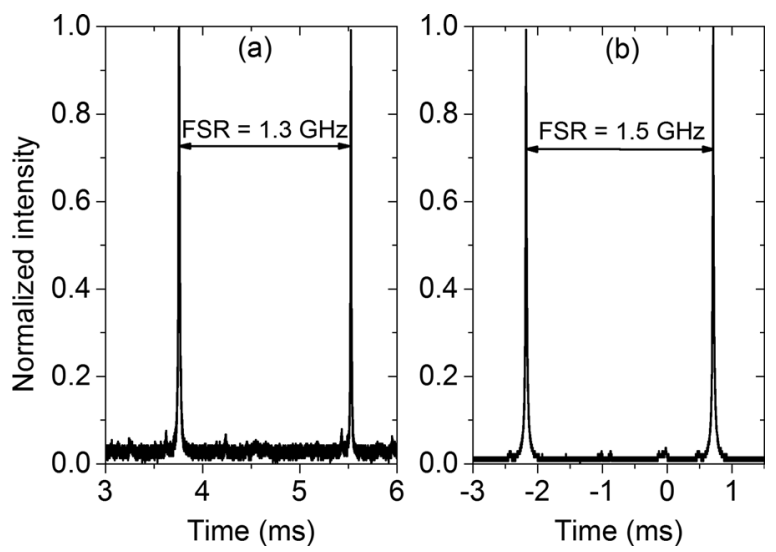

FIG. 4. Scanning FPI traces of the $807.5 \mathrm{~nm}$ laser (a) and the $1063.5 \mathrm{~nm}$ laser (b) showing single-frequency operation.

The wavelength of the blue light can be tuned by changing the wavelength of either of the two infrared lasers and simultaneously changing the PPKTP temperature to assure phase matching. By tuning the $808 \mathrm{~nm}$ laser from $806 \mathrm{~nm}$ to $810.5 \mathrm{~nm}$, we have tuned the blue light in the $458.5-460 \mathrm{~nm}$ range. If the entire tuning ranges of the tapered amplifiers could be phase matched in the nonlinear crystal, a tuning range of 451-468 $\mathrm{nm}$ could be reached. A different selection of tapered amplifier wavelengths and nonlinear crystal can expand this wavelength range to cover most of the visible spectral range and also parts of the UV region are accessible.

The beam quality of the generated blue light is determined partly by the beam circulating in the enhancement cavity, partly by the beam quality of the single-pass beam, and partly by the focusing of the single-pass beam. As shown by Karamehmedović et al., ${ }^{16}$ it is possible to use the SFG process with a Gaussian beam to clean up a non-Gaussian incoming beam by properly choosing the overlap between the two beams. In our case, we have the Gaussian beam from the cavity and the near-Gaussian beam from the tapered laser and the resulting generated beam is nearly diffraction limited with $\mathrm{M}^{2}<1.15$ in both directions. The beam caustic through the focus region is shown in Fig. 5 where the beam profiles in the vertical and horizontal directions are included.

The power stability of the current setup is limited by the nonlinear crystal. On short time scales, the power is stable to within $\pm 4 \%$. This power stability is obtained in an entirely passively locked system with no precautions taken to minimize temperature fluctuations caused by air flows and with all components placed separately on an optical table. Without the intracavity YAG etalon, the power fluctuations were significantly larger in the range of $\pm 25 \%$. This is attributed to resonance peak mismatch between the two cavities. On long time scales, we see a slow power drop, which is attributed to losses in the PPKTP crystal. The power drop could be an indication of either blue-induced infrared absorption or grey tracking in the PPKTP crystal.

In summary, we have demonstrated a generic approach for generation of single-frequency tunable light in the visible spectral range. The method includes a tapered amplifier operated in a coupled cavity to boost the circulating power

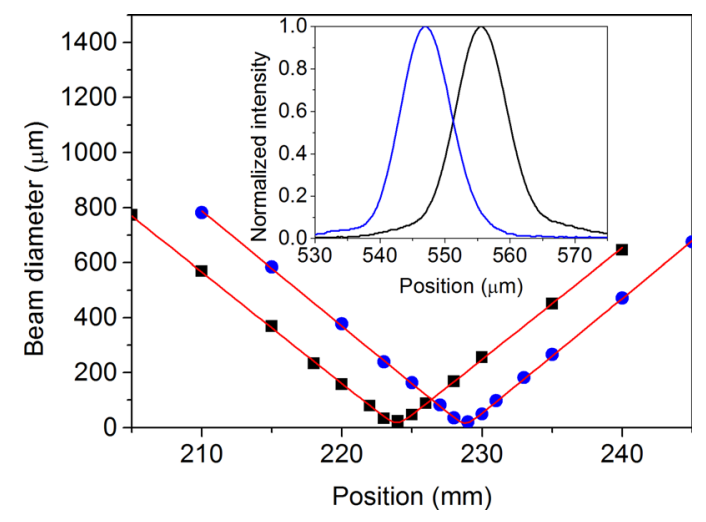

FIG. 5. Beam caustics through a focus for the vertical (dots) and horizontal (squares) direction. The lines are hyperbolic fits. The inset shows the beam profiles in the focus in the two axes. The plots are off-set for clarity.

in a SFG crystal and a single-pass laser. The method presented in this paper is a generic approach to SFG since it allows efficient generation of tunable light at almost any visible wavelength. We applied this approach to a tapered amplifier in a coupled ring cavity setup using SFG with a single-pass tapered diode laser in a nonlinear PPKTP crystal. In this demonstration, we extracted $340 \mathrm{~mW}$ of singlefrequency light around $459 \mathrm{~nm}$ with nearly diffraction limited beam quality. We have demonstrated a tuning range of $1.5 \mathrm{~nm}$ and significantly larger tuning is possible by using a different nonlinear crystal. This approach can easily be expanded to cover other spectral regions.

We gratefully acknowledge the Ferdinand-Braun-Institut, Leibnitz-Institut für Höchstfrequenztechnik for providing the tapered amplifiers used in this work.

${ }^{1}$ J. Yue, C.-Y. She, B. P. Williams, J. D. Vance, P. E. Acott, and T. D. Kawahara, Opt. Lett. 34, 1093 (2009).

${ }^{2}$ T. Nishikawa, A. Ozawa, Y. Nishida, M. Asobe, F.-L. Hong, and T. W. Hänsch, Opt. Express 17, 17792 (2009).

${ }^{3}$ S. Johansson, S. Spiekermann, S. Wang, V. Pasiskevicius, F. Laurell, and K. Ekvall, Opt. Express 12, 4935 (2004).

${ }^{4}$ A. Müller, O. B. Jensen, K.-H. Hasler, B. Sumpf, G. Erbert, P. E. Andersen, and P. M. Petersen, Opt. Lett. 37, 3753 (2012).

${ }^{5}$ W. P. Risk, J.-C. Baumert, G. C. Bjorklund, F. M. Schellenberg, and W. Lenth, Appl. Phys. Lett. 52, 85 (1988).

${ }^{6}$ J. Janousek, S. Johansson, P. Tidemand-Lichtenberg, S. Wang, J. Mortensen, P. Buchhave, and F. Laurell, Opt. Express 13, 1188 (2005).

${ }^{7}$ K. P. Sørensen, P. Tidemand-Lichtenberg, and C. Pedersen, Laser Phys. Lett. 8, 209 (2011).

${ }^{8}$ E. Karamehmedovic, C. Pedersen, M. T. Andersen, and P. TidemandLichtenberg, Opt. Express 15, 12240 (2007).

${ }^{9}$ W. P. Risk and W. Lenth, Appl. Phys. Lett. 54, 789 (1989).

${ }^{10}$ S. Vasilyev, A. Nevsky, I. Ernsting, M. Hansen, J. Shen, and S. Schiller, Appl. Phys. B 103, 27 (2011).

${ }^{11}$ P. N. Kean, R. W. Standley, and G. J. Dixon, Appl. Phys. Lett. 63, 302 (1993).

${ }^{12}$ E. Mimoun, L. De Sarlo, J.-J. Zondy, J. Dalibard, and F. Gerbier, Opt. Express 16, 18684 (2008).

${ }^{13}$ D. Skoczowsky, A. Jechow, R. Menzel, K. Paschke, and G. Erbert, Opt. Lett. 35, 232 (2010).

${ }^{14}$ O. B. Jensen and P. M. Petersen, Opt. Express 21, 6076 (2013).

${ }^{15}$ M. Chi, O. B. Jensen, J. Holm, C. Pedersen, P. E. Andersen, G. Erbert, B. Sumpf, and P. M. Petersen, Opt. Express 13, 10589 (2005).

${ }^{16} \mathrm{E}$. Karamehmedović, C. Pedersen, O. B. Jensen, and P. TidemandLichtenberg, Appl. Phys. B 96, 409 (2009). 